\title{
Verdade e idealização: a busca do autor Nick Tosches por uma experiência sensorial única em A última casa de ópio ${ }^{i}$
}

\author{
Bibiana Barrios Simionatto \\ Mestranda em Escrita Criativa pela Pontifícia Universidade Católica do Rio Grande do Sul \\ (PUC-RS) \\ bibianabsimionatto@gmail.com
}

\section{RESUMO}

Por que a procura por substâncias entorpecentes mantém-se alta ao longo dos tempos? $\mathrm{E}$ por que essa busca hedonista por uma sensação que mimetize uma espécie de paraíso na terra é tão valorizada e glamourizada na literatura, na música e no cinema? O autor Nick Toshes aborda essa e outras questões esclarecedoras no livro $A$ última casa de ópio, publicado pela primeira vez em Nova York (1985) com o título The last opium den. A publicação de Toshes serviu como ponto de partida para os objetivos deste artigo: investigar desejos e a busca por experiências únicas num mundo dominado pela cultura de massa.

Palavras-chave: literatura e viagem, ópio, experiências únicas.

\begin{abstract}
Why has the demand for narcotic substances kept high over time? And why is this hedonistic quest for a sensation that mimics a kind of paradise on earth so valued and glamorized in literature, music, and cinema? Nick Toshes addresses this and other enlightening questions in his book The Last Opium House, first published in New York (1985). The Toshes book served as a starting point for the purposes of this article: to investigate desires and the search for unique experiences in a world dominated by mass culture.
\end{abstract}

Keywords: literarture and travel, opium, unique experiences. 
O narrador, um americano de idade não revelada, vive em Nova York e se apresenta como um admirador das artes, da literatura e da história. Inicia seu relato criticando a onda gourmet de apreciadores pseudo-entendidos que envolvia (e até hoje envolve) a gastronomia e a enologia. Detém-se um bom tempo, inclusive, criticando os consumidores de vinho e suas maneiras afetadas de degustação. Mostra-se um tanto misantropo quando classifica hábitos de consumo, que considera típico dos neo-cafoni, um pequeno grupo que compra experiências únicas a peso de ouro, mais por ostentação do que prazer.

O narrador não quer fazer parte deste grupo patético e superficial. Se é para ter uma experiência sensorial única, ele prefere buscar a mesma substância que os poetas e pensadores do passado consumiam. Ele quer visitar o inferno ou chegar às portas do paraíso, elevar-se aos níveis de consciência de Homero e Shakespeare. Ele deseja as mesmas sensações do homem pré-histórico, dos habitantes da Mesopotâmia e do Egito antigo. Ele precisa experimentar o ópio.

“Ninguém, tendo uma vez provado o luxo divino do ópio, descerá depois aos asquerosos e mortais prazeres do álcool" (TOSCHES, 2006, p. 17). Thomas De Quincey (1785-1859) não chegou a fumar o ópio, nem mesmo a comê-lo, como o título da obra Confissões de um comedor de ópio sugere. O autor passou a ingeri-lo aos 19 anos, na forma de gotas, para aliviar o sofrimento gástrico e combater sintomas de tuberculose. No início utilizou-o uma vez a cada três semanas, depois reduziu o espaçamento das doses para uma vez por semana. Em 1813, após uma severa desordem gástrica, passou a ingeri-lo diariamente. Como o organismo tende a tolerar a substância e exigir doses cada vez mais elevadas, em 1816, De Quincey necessitava de 8 mil gotas (320 grãos) por dia, dosagem que posteriormente aumentou para 480 grãos diários (MOTTA, 2005). 
De Quincey tinha motivos para considerar o álcool um produto asqueroso. No início do século XIX o Ocidente não conhecia os cachimbos para fumar ópio. A apresentação da droga era na de forma deláudano, uma tintura onde o ópio era diluído em álcool. Nesta apresentação, 25 gotas de láudano continham um grão de ópio. “Assim, por mais celestial que fossem, os efeitos da droga eram degradados e amortecidos pela esmagadora proporção do ‘asqueroso e mortal’ álcool” (TOSCHES, 2006, p. 17).

Mesmo assim, De Quincey não se furta de contar, com admirável devoção, as experiências com a droga que, mesmo não consumida em sua forma pura, levou-o a excitantes estados de consciência e pensamentos elevados. Tanto que o livro só se torna realmente interessante a partir da parte II, quando o narrador (não por conta das dores estomacais, mas em função de uma dor de dente) adentra uma farmácia e compra a tintura de láudano para aliviar seu tormento que dura mais de 15 dias. É a partir de então, no capítulo Os prazeres do ópio, que De Quincey escreve uma defesa apaixonada à substância desmentindo advertências médicas e notícias de jornais. Afirma que não há perigo de intoxicação, que o abuso do produto intoxica somente por exagero de álcool, nunca de ópio (DE QUINCEY, 1982, p. 47-49).

No século III a.C., o filósofo, botânico e médico grego Teofrasto foi quem primeiro descreveu e denominou a substância originária da papoula (Papaver somnuriferum). Obtido através de cortes e macerações das cápsulas da planta madura, o fluido leitoso com propriedades narcóticas recebeu o nome de opium. Muitos séculos depois, o médico inglês Thomas Sydenham (1624-1689) desenvolveu o láudano com intenção de uso terapêutico. A partir de então, o comércio do opióide proliferou tanto que gerou conflitos entre China e Inglaterra, conhecidos como as guerras do ópio (1839-1842). Como 
resultado, a Inglaterra vitoriosa tomou o porto de Hong Kong, estabelecendo um caminho marítimo do ópio para a Europa (PRETO, 2005).

Quando afirma que deseja experimentar a droga nos mesmos moldes como imagina e romantiza as casas de ópio do início do século $\mathrm{XX}$, o narrador não se move apenas por uma curiosidade idílica. Adiante, ele explica que sofre de diabetes e não consegue controlar a doença, apesar dos esforços empreendidos. A condição se torna motivo decisivo para o personagem planejar sua viagem em busca da última casa de ópio.

Na obra Teoria da viagem, o filósofo hedonista Michel Onfray nos convida a refletir quando realmente inicia uma viagem. É no exato momento em que o viajante fecha a porta de casa e deixa para trás o domicílio, o porto de matrícula, afirma Onfray (2009, p. 35). Mas antes disso, há o gesto, o interesse, a vontade da viagem, seguidos pela biblioteca, a pesquisa sobre o lugar que desejamos conhecer. Toshes nunca fumou o ópio, mas conhece com detalhes o ritual:

De Quincey jamais fumou ópio. Se o tivesse feito, só se pode imaginar até onde sua extravagante reverência teria se estendido. Mas, como as origens do matrimônio sagrado entre homem e ópio se perdem na névoa primordial, também se perdem as da Grande Tragada. Existe o relato, geralmente aceito como verdadeiro, de que os holandeses apresentaram aos chineses a prática de fumar ópio num cachimbo de tabaco, no início do século XVIII. Mas é impossível "fumar" ópio num cachimbo de tabaco, uma vez que o ópio não queima e nem se converte em fumaça. Em vez disso, ele é sublimado em vapor mediante uma química bastante diferente da de qualquer outro processo de defumação. O processo, ou arte, desta química, embora bastante simples quando dominado, requer muitas coisas: a combinação precisa entre o óleo adequado para a lamparina, o seu formato e o de seu bocal, e o pavio, de fibra apropriada e cortado na medida certa; habilidade ao empregar a fina haste para aquecer, girar e sovar o ópio - isso sem falar na demorada preparação prévia da droga - antes de sua inserção no pequeno orifício do bojo, ou dissipador, do cachimbo; a distância e o ângulo de inclinação, manipulados com precisão, do bojo do cachimbo 
sobre a chama da lâmpada. Tudo isso é fundamental para manter o grau exato do calor latente necessário para converter o ópio em vapor (TOSCHES, 2006, p. 20-21).

O culto aos hábitos antigos, a admiração pelos rituais e o repúdio aos costumes fúteis da sociedade atual aproximam Tosches de Onfray. Tosches busca a planta do prazer dos sumérios, o remédio de Deus, o ritual da Era do Bronze. Mais ainda, ele busca o odor do ópio no hálito de Deus, soprado nas narinas de Adão. Onfray rememora os tempos das viagens raras, quando o turismo era inexistente, o tempo lento e os espaços de comunicação e trocas preservado. Não havia tantas quinquilharias intelectuais, lamenta.

\begin{abstract}
Viajar supõe menos o espírito missionário, nacionalista, eurocêntrico e estreito, do que a vontade etnológica, cosmopolita, descentrada e aberta. O turista compara, o viajante separa. $O$ primeiro permanece à porta de uma civilização, toca de leve uma cultura e se contenta em perceber sua espuma, em apreender seus epifenômenos, de longe, como espectador engajado, militante de seu próprio enraizamento; o segundo procura entrar num modo desconhecido, sem intenções prévias, como espectador desengajado, buscando nem rir nem chorar, nem julgar nem condenar, nem absolver nem lançar anátemas, mas pegar pelo interior, que é compreender, segundo a etimologia. 0 comparatista designa sempre o turista, o anatomista indica o viajante (ONFRAY, 2009, p. 58-59).
\end{abstract}

Antes de iniciar a viagem que o livro fala, Tosches (podemos chamar o autor de narrador, pois ele assume, em entrevista posterior, que o livro é uma mistura de ficção, jornalismo, literatura e lenda) (MATIAS, 2006) procurou uma casa de ópio durante dois anos. Envolveu-se com pessoas das camadas menos respeitáveis da sociedade e percorreu Londres, Paris, Berlim, Nova York e Roma, sem sucesso algum. A uma certa altura, um marchand turco apresentou-Ihe uma substância que supostamente seria ópio. 
Desconfiado, recusou-se a experimentar. Queria o cachimbo, o ritual, a casa com cortinas de brocado, almofadas de veludo e o suave aroma da substância celestial.

Iniciou sua viagem em Hong Kong, única cidade que considerava verdadeiramente capitalista no mundo. Ao desembarcar, entretanto, relata a decepção: o comunismo tingiu de cinza o neon dos esplendorosos dragões chineses. Sai para jantar com um amigo e surpreende-se com os hábitos alimentares locais. Discorre sobre o cozimento de caranguejos vivos e a retirada de bexiga de uma cobra para tratar artrite. O exótico oriental segue provocando assombro e fascinação no homem do Ocidente. Após o jantar, sai às ruas em busca das famosas salas de fumaça e flores, onde as flores eram as cortesãs e a fumaça o ópio. Encontra grande oferta de flores, nenhuma de fumaça. $\mathrm{Na}$ Hong Kong de domínio chinês não existem mais casas de ópio, a última e mais miserável fechara muitos anos atrás, o amigo conta. Nem em Xangai, onde a prostituição infantil tornou-se atração turística, encontram-se salas de fumaça e flores.

A parada seguinte, Bangcoc, também oferece um submundo de miséria e prostituição onde garotas de pouca idade aceitam tudo quanto é tipo de perversão por alguns dólares americanos. Como era de se esperar, há nova excursão culinária. Gafanhotos fritos e filhotes de pardais carbonizados estão nos cardápios dos restaurantes e botecos de rua. Nova decepção, apesar de apresentar um submundo mais grotesco, Bangcoc também não possui salas de fumaça e flores. Na saída da Tailândia, Tosches lança uma crítica mordaz a outro subproduto da sociedade atual: as redes de fast food que se proliferam pelo mundo. Imperdível o novo café Starbucks, ironiza.

É apenas no Camboja que Tosches consegue ter a primeira experiência com a droga desejada. Um amigo o leva de moto até uma cabana de palafitas, paredes forradas de bambu e folhagens trançadas onde o morador o recebe com um sorriso no rosto. 
Parece um homem muito feliz, observa Tosches. Neste ponto, com visível emoção, o autor narra o passo a passo da preparação do cachimbo e do ópio. Relata sobre os aromas, a posição para deitar-se e aspirar o bocal, a cova nas bochechas, característica de quem força a musculatura para inalar o ópio e as sensações de elevação que experimenta ao fumar contemplando as estrelas.

Segundo Tosches, as drogas originárias do ópio são bem mais rentáveis. Ele diz achar uma vergonha o fato de podermos comprar não só heroína, como cocaína, crack e até armamentos em qualquer beco enquanto o ópio é difícil de encontrar. $\mathrm{O}$ autor culpa a cultura consumista, pois o ópio vale mais dinheiro quando se transforma em heroína. Além disso, a heroína dá a sensação de pressa, o efeito se anuncia rápido. Diferente do ópio, que precisa de tempo para saborear, por isso é denominado uma lenta e luxuosa sedução (MATIAS, 2006).

A invenção da inocência necessária à viagem exige, pois, o abandono das opiniões sobre o espírito dos povos, a recusa do olhar egocêntrico e missionário, mas também livrar-se dos preconceitos sobre a forma da viagem. Pois quase todos os autores especializados no assunto celebram a imersão, enaltecem o mérito das longas temporadas e dos investimentos novos - a aprendizagem da língua, o domicílio no local, a vida com os autóctones. Com quais objetivos? Compreender um país, captar sua natureza essencial, sentir verdadeiramente seu sabor? Dispor de uma inteligência ativa no interior dessa cultura, quando os seus nativos não a possuem? (ONFRAY, 2009, p. 60)

Na parada seguinte, o narrador é apresentado ao chandoo, a purificação do ópio bruto. Alguns itens devem ser observados ao fumá-lo: a escolha do óleo, a quantidade a ser colocada no reservatório da lamparina, os materiais e a construção da lamparina, a haste, o raspador. $\mathrm{O}$ anfitrião, um homem de posses que conta sobre pessoas influentes 
que armazenam o ópio em recipientes de prata durante anos, finalmente indica o endereço da sonhada casa de ópio.

Na Indochina, numa palafita miserável, sem as cortinas de brocado e as almofadas de veludo, o autor é recebido por um homem sem camisa e depois por um velho de passos vacilantes. O velho recebe a encomenda enviada pelo anfitrião da casa anterior, um pacote de chá, e oferece uma esteira para o visitante. O narrador se convence que a visão que tinha das antigas casas de ópio é uma idealização que pouco ou nada tem a ver com a realidade. A maioria delas era um ambiente de miséria e degradação. O fim da vida dos viciados em ópio é doloroso, o corpo exige cada vez mais droga e a abstinência pode causar a morte.

O velho satisfaz-se com o presente e dá a entender, na língua local, que nada será cobrado. Dinheiro é algo que não importa muito por ali. Tosches se deita na esteira indicada, posiciona-se de lado, abocanha o cachimbo e sente-se em casa.

O ter me aliviado das minhas dores era agora insignificante diante de meus olhos: todo aspecto negativo foi tragado pela imensidade daqueles efeitos positivos que se abriram diante de mim, no abismo da alegria então repentinamente revelada. Havia encontrado uma panacéia para todos os males humanos: aqui estava o segredo da felicidade, sobre a qual os filósofos haviam discutido durante tantos anos. A felicidade podia agora ser comprada com uma moeda e carregada no bolso do casaco: êxtases portáteis poderiam ser engarrafados e a paz de espírito poderia ser remetida em galões pela diligência do correio (DE QUINCEY, 1982, p. 48).

Através do desprezo que Tosches demonstra pela banalização das drogas e monetização da indústria farmacêutica, não é difícil compreender seu fascínio pela substância praticamente extinta no final do século XX. Em seu texto, uma espécie de rapsódia ao ópio, De Quincey relata a experiência após a primeira dose como um 
apocalipse do mundo inteiro dentro de si, a ascensão dos mais profundos abismos de seu espírito. Reserva, portanto, o sofrimento para a última parte de suas confissões, período após 1817. Há um capítulo em que introduz as dores do ópio, como um texto preparatório para o que vem a seguir: as dores do ópio propriamente ditas, onde De Quincey conta sobre o isolamento, a dificuldade de concentração, de leitura e de escrita, o total desdém com as contas da casa e os terríveis sonhos que muito lembram alucinações, embora Tosches tenha afirmado que, de todas as drogas, o ópio é a menos alucinógena. De Quincey, por outro lado, afirma que é a menos entorpecente. E termina seu relato com notável admiração a sua companheira de anos:

O interesse do leitor judicioso não deve se prender aos fascinantes efeitos do ópio, mas ao seu fascinante poder. Não o comedor de ópio, mas o próprio ópio é o verdadeiro herói desta narrativa e o centro de todas as preocupações. $O$ objetivo foi mostrar os fantásticos efeitos do ópio, quer no prazer, quer na dor; e se consegui, esta narrativa deve darse por encerrada (DE QUINCEY, 1982, p. 78-79).

Há muito de lenda nas especulações sobre o vício de Thomas De Quincey. O próprio autor diz que Confissões de um comedor de ópio traz verdades, mas não todas. Há um desacordo com informações relatadas em outros artigos citados anteriormente. $\mathrm{O}$ autor, porém, na primeira versão do livro, comenta que seu extremo de consumo foi 150 grãos por dia. Nesta época, com o corpo em sofrimento, decidiu reduzir para 40, depois 30 até chegar a uma dúzia. Triunfou, mas fala sobre agitações, dores, palpitações, situações similares à torturas físicas. Consumiu o láudano por mais de 50 anos e morreu em 1859. A primeira versão de Confissões saiu de um quarto de York Street, Londres, em fins de agosto de 1821 com autoria desconhecida. Foi publicada em forma de livro em 1822 e somente em 1856, De Quincey resolveu revisá-la. Enfrentando a pobreza e perdas 
familiares, o homem de 70 anos que reescreveu as Confissões era bem diferente do de 36 que escreveu a primeira versão.Vivia em quartos infectos, comia mal e andava de noite para dormir durante o dia. Era considerado um excêntrico, incapaz de lidar com dinheiro, horários e datas (DE QUINCEY, 1982, p. 10-11).

O escritor Nick Tosches nasceu em Newark, Nova Jersey, EUA, em 17 de outubro de 1949, é jornalista e vive em Nova York. Publicou seu primeiro livro Country, em 1977, sobre os diversos ritmos que originaram o rock'nroll. Tem 15 livros, incluindo Hellfire, uma biografia do músico Jerry Lee Lewis (1982). Seu último livro foi lançado em 2015, com o título UnderTiberius. ${ }^{\text {ii }}$

\section{Referências}

BACHELARD, G. Pureza e purificação. A moral da água. In: A água e os sonhos. Tradução Antônio de Pádua Danesi. São Paulo: Martins Fontes, 1997.

CHEVALIER, J. Dicionário de símbolos: mitos, sonhos, costumes, gestos, formas, figuras, cores, números. 24. ed. Rio de Janeiro: José Olympio, 2009.

CORTÁZAR, J. Alguns aspectos do conto. In: Valize de cronópio. 2. ed. São Paulo: Perspectiva, 1993.

DELEUZE, G. Crítica e clínica. Tradução Peter Pál Pebart. São Paulo: Ed. 34, 1997.

FAYAD, Maria Elizete de Azevedo. Poesia e realismo em Rio do Sono de José Godoy Garcia. 2009. 90f. Dissertação (Mestrado em Letras) - Programa de Pós-Graduação em Literatura, Pontifícia Universidade Católica de Goiás, Goiânia. 2009.

FOUCAULT, Michel. Stultifera navis. In: História da loucura. São Paulo:

Perspectiva, 2003.

. Bartleby, ou a fórmula. In: Crítica e clínica. 2. ed. Tradução Peter Pál Pelbart. São Paulo: Editora 34, 2011, p. 91-117.

GARCIA, José Godoy. Florismundo Periquito. Brasília: Thesaurus, 1990. 
GARCIA, José Godoy. Poesia. Brasília: Thesaurus, 1999.

HOHLFELDT, Antonio Carlos. Conto brasileiro contemporâneo. 2. ed. rev. e ampl. Porto Alegre: Mercado Aberto. 1988.

Recebido em 22 de agosto de 2018.

Aceite em 11 de março de 2019.

\footnotetext{
' O presente trabalho foi realizado como apoio da Coordenação de Aperfeiçoamento de Pessoal de Nível Superior - Brasil (CAPES) - Código de Financiamento 001./This study was financed in part by the Coordenação de Aperfeiçoamento de Pessoal de Nível Superior - Brasil (CAPES) - Finance Code 001.

ii Informações retiradas do site pessoal de Nick Tosches.
} 